\title{
ANALISIS PEMASARAN BERAS DI KECAMATAN SIDOREJO KOTA SALATIGA
}

\author{
(The Analysis Of Rice Marketing In Sub-Disctrict Sidorejo, Salatiga City)
}

\author{
Ria Rosdiana Silaban ${ }^{1}$, Yuliawati ${ }^{2}$ \\ Fakultas Pertanian dan Bisnis, Universitas Kristen Satya Wacana Salatiga \\ Jl. Diponegoro N0.52-60, Salatiga, Kec. Sidorejo Tengah \\ Email : ria12.silaban@gmail.com ${ }^{1}$, yuliawati.fpb@uksw.edu ${ }^{2}$
}

Article Submitted : 28-08-2019

Article Accepted : 03-10-2019

\begin{abstract}
Rice is a staple for $95 \%$ of the population of Indonesia, demand for rice on market reaches $139 \mathrm{~kg} / \mathrm{capita}$ year which has an impact on demand and the price of rice is high. Trading institutions marketing is one the effects of high grain and rice prices. This results in high cost of marketing margin distribution. This study aimed to investigate the pattern of rice marketing channels, the margin of each institution, and the efficiency of rice marketing channels. This research used descriptive quantitative methods. The data collection was done by purposive sampling through observation and interviews using questionnaires with 30 samples of rice farmer respondents. Samples for rice marketing channel patterns used snowball sampling technique. The analytical methods used were marketing margin analysis, marketing channel profits, farmer's share and marketing efficiency. The results showed that there were three patterns of rice marketing channels, namely: Brokers, Grinder and Farming Communitie. Margin of trading channel I for Pandan Wangi rice was Rp 7.200/kg or 56,7\% and IR64 rice Rp 5.800/kg or 52,7\%; the margin of trading channel II to Pandan Wangi rice was $7.200 / \mathrm{kg}$ or $57,6 \%$ and IR64 rice Rp $5.600 / \mathrm{kg}$ or $52,8 \%$ and the margin of trading channel III to Pandan Wangi rice was Rp 5.500/kg or $56,3 \%$ and IR64 rice $5.500 / \mathrm{kg}$ or $51,4 \%$. The highest farmer's share value was found in channel III where Pandan Wangi rice was 43,7\% and IR64 was 48,6\%. The most efficient marketing of the three channels was in channel III which Pandan Wangi was 29,8\% and IR64 was $33,4 \%$.
\end{abstract}

Keywords: marketing efficiency, farmer's share, trading margin, rice marketing.

\section{PENDAHULUAN}

Sektor pertanian merupakan penyedia pangan bagi masyarakat Indonesia dan menjadi sektor unggulan bagi devisa negara. Subsektor pertanian yang merupakan andalan pemerintah yaitu tanaman pangan. Salah satu komoditas tanaman yang banyak dikelola oleh masyarakat adalah padi atau beras (Jayanti, 2011). Beras sebagai bahan pokok bagi $95 \%$ penduduk Indonesia yang mencapai 237 juta jiwa (BPS, 2008). Permintaan beras di pasar mencapai $139 \mathrm{~kg}$ per kapita per tahun berdampak pada permintaan beras yang meningkat dan menyebabkan harga beras menjadi tinggi ( Malian, 2004)

Pengembangan produk pertanian dari segi ekonomi tergantung dari tingkat penghasilan dan kelayakan usaha yang diperoleh. Hal ini didukung dengan metode pemasaran yang lancar dan dengan margin pemasaran yang sebanding, sehingga lebih meningkatkan petani dalam berusaha lebih baik. Upaya perbaikan saluran pemasaran memiliki peran berarti dikarenakan upaya peningkatan hasil produksi saja tidak 
sepenuhnya mampu memajukan penghasilan petani jika tidak didukung oleh saluran pemasaran yang efektif dan keadaan pasar yang terus berubah. Besarnya biaya pemasaran hasil produk petani mampu mempengaruhi harga di konsumen dan harga pada petani (Nurasa dan Darwis, 2007)

Tambunan (2008) menyatakan dalam pemasaran beras ada dua jalur yang digunakan yaitu jalur swasta dan pemerintah (Bulog). Dalam hal ini biasanya jalur swasta yang memiliki jalur lebih panjang karena banyaknya agen yang terlibat dimulai oleh pengepul desa, penggiling padi, grosir dan yang terakhir pedagang eceran, setiap barang yang berpindah tangan agen biasanya akan menambah harga barang dari harga awal sehingga barang yang sampai ke konsumen akhir cenderung lebih mahal.

Dari hasil wawancara lapangan yang sudah dilakukan dengan petani padi di Kecamatan Sidorejo, terdapat permasalahan dalam pemasaran hasil panen padi seperti, petani yang lambat mengetahui perubahan informasi harga gabah basah sehingga menjual hasil panen langsung ke tengkulak atau penggiling padi dengan harga yang sudah ditetapkan oleh lembaga tersebut. Hal ini menyebabkan keuntungan paling tinggi akan diperoleh lembaga tertentu, sementara petani yang sudah memproduksi padi biasanya mendapatkan keuntungan yang lebih kecil. Ditambah jika akses jalan jauh dari lahan pertanian maka harga jual hasil panen petani akan menurun.

Berdasarkan permasalahan tersebut memotivasi peneliti dalam melakukan penelitian dengan topik Analisis Pemasaran Beras di Kecamatan Sidorejo Kota Salatiga, dengan tujuan penelitian Mengetahui saluran pemasaran beras dari petani sampai konsumen akhir, mengetahui besar margin yang diperoleh di setiap lembaga pemasaran beras dan mengetahui efisiens saluran pemasaran beras.

\section{METODE PENELITIAN}

Kegiatan penelitian dilaksanakan dari bulan April-Juni 2019 di Kecamatan Sidorejo Kota Salatiga yang dipilih secara purposive dikarenakan Kecamatan Sidorejo merupakan wilayah penghasil padi atau beras terbesar di Kecamatan di Kota Salatiga dengan luas lahan sawah Sidorejo 315 (ha), Tingkir 300 (ha), Sidomukti 50 (ha), dan Argomulyo 9 (ha) (Dinas Pertanian, 2017). Jenis penelitian menggunakan tipe penelitian deskriptif kuantitatif. Teknik pengambilan sampel untuk responden petani dilakukan secara sengaja (purposive sampling) sebesar 30 responden untuk petani padi, dengan kriteria petani padi di Kecamatan Sidorejo yang menjual produknya ke saluran pemasaran tertentu. Pengambilan sampel berkaitan dengan pola saluran pemasaran beras di lakukan dengan teknik snowball sampling, dengan menggunakan unit analis yaitu lembaga-lembaga yang terkait dalam pemasaran beras.

Data penelitian terdiri dari data sekunder dan data primer. Data sekunder diperoleh dari Dinas Pertanian Kota Salatiga, Badan Pusat Statistik (BPS) Kota Salatiga dalam angka, buku-buku literatur penunjang, jurnal, skripsi, dan lembaga atau instansi yang terkait dalam penelitian ini. Data primer diperoleh melalui wawancara dengan menggunakan kuisoner sebagai alat pemandu pertanyaan.

Metode pengolahan dan analisis data penelitian menggunakan analisis deskriptif dan analisis kuantitatif. Analisis deskriptif analisa dengan menggambarkan keadaan obyek penelitian dengan acuan berdasarkan kebenaran yang ada dan terlihat. Analisis ini dilakukan untuk mengetahui bagaimana pola pemasaran dan lembaga-lembaga terkait dalam pemasaran.

Analisis kuantitatif, metode menggunakan data berupa angka sebagai alat menganalisis. Dalam penelitian ini analisis kuantitatif yang digunakan terdiri dari :

Analisis Margin Pemasaran 
Margin pemasaran selisih dari harga jual gabah di tingkat petani dengan harga jual beras di tingkat konsumen (Anindita, 2003).

Untuk petani :

$\mathrm{Mp}=\mathrm{Pr}-\mathrm{Pf}$

Keterangan:

$\mathrm{Mp}=$ Margin Pemasaran $(\mathrm{Rp} / \mathrm{kg})$

$\%$ margin pemasaran

Petani $=\frac{\text { Harga penjualan gabah basah }}{\text { Harga beras eceran akhir }} \times 100 \%$

Tengkulak, penggiling dan gapoktan $=\frac{\text { Margin antara petani tiap lembaga }}{\text { Harga eceran akhir }} \times 100 \%$

Pedagang pengecer $=\frac{\text { Margin antara petani tiap lembaga dan pengecer }}{\text { Harga eceran akhir }} \times 100 \%$

Keuntungan lembaga:

$$
\mathrm{Ki}=\mathrm{Hji}-\mathrm{Hbi}-\mathrm{Bpi}
$$

Keterangan :

$\mathrm{Hji}=$ Harga jual lembaga pemasaran ke-i

$\mathrm{Hbi}=$ Harga beli lembaga pemasaran ke-i

Bpi=Biaya lembaga pemasaran kei (Sudiyono, 2004).

Farmer's share. Untuk mengetahui berapa besar bagian yang diterima oleh petani dari harga di tingkat konsumen:

$\mathrm{Fs}=\mathrm{Hj} / \mathrm{He} \mathrm{X} 100 \%$

Keterangan :

Fs $=$ Farmer's share

$\mathrm{Hj}=$ Harga di tingkat petani $(\mathrm{kg})$

$\mathrm{He}=$ Harga di tingkat pengecer $(\mathrm{kg})$

Efisiensi pemasaran beras dari petani ke pedagang atau dari produsen ke pengecer diperoleh dengan menggunakan rumus
$\mathrm{Pf}=$ Harga tingkat produsen $(\mathrm{Rp} / \mathrm{kg})$

$\mathrm{Pr}=$ Harga tingkat konsumen $(\mathrm{Rp} / \mathrm{kg})$

Untuk tiap lembaga :

$\mathrm{Mmlp}=\mathrm{Ps}-\mathrm{Pb}$

Keterangan :

Mmlp= Margin tingkat lembaga pemasaran

Ps = Harga jual setiap tingkat lembaga

$\mathrm{Pb}=$ Harga beli setiap tingkat lembaga

\section{Saluran Pemasaran I}

Keterangan :

$$
\mathrm{Eps}=\frac{\mathrm{Bp}}{\mathrm{He}} \times 100 \%
$$

Eps $=$ Efisiensi pemasaran

$\mathrm{Bp}=$ Biaya pemasaran $(\mathrm{Rp} / \mathrm{kg})$

$\mathrm{He}=$ Harga eceran $(\mathrm{Rp} / \mathrm{kg})$

$0-33 \%=$ Efisien

$34-67 \%=$ Kurang efisien

$68-100 \%=$ Tidak efisien (Soekartawi, 2002)

\section{HASIL DAN PEMBAHASAN}

\section{Saluran Pemasaran Beras}

Terdapat tiga pemasaran beras di Kecamatan Sidorejo dengan melibatkan tiga lembaga terkait yaitu: petani padi, tengkulak, penggiling padi, dan gapoktan dengan menggunakan tiga saluran pemasaran yaitu :

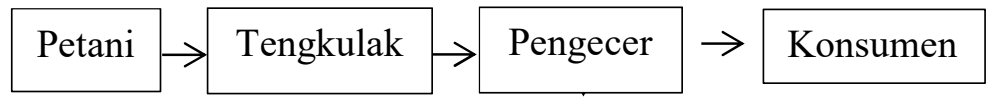

Gambar 1. Saluran I

Dari gambar I diatas dapat dilihat beras sampai ke tangan konsumen dengan melewati dua lembaga pemasaran tengkulak dan pengecer. Tengkulak membeli gabah basah dari petani langsung dengan sistem tebasan. Panen dan pengangkutan gabah dilakukan oleh tengkulak sehingga petani tidak mengeluarkan biaya panen. Ada dua jenis padi yang ditanam oleh petani yaitu
Pandan wangi dan IR64. Harga gabah basah tengkulak ke petani Pandan Wangi Rp 5.500/kg, IR64 Rp 5.200/kg. Pembayaran dilakukan secara tunai atau kredit tergantung kesepakatan bersama. Gabah diproses menjadi beras oleh tengkulak dan dijual ke pengecer dengan harga Pandan wangi $\mathrm{Rp}$ $11.900 / \mathrm{kg}$, IR64 Rp 9.800/kg. Pengecer menjual beras kepada konsumen akhir 
Pandan wangi Rp 12.700/kg dan IR64 Rp 11.000/kg.

\section{Saluran Pemasaran II}

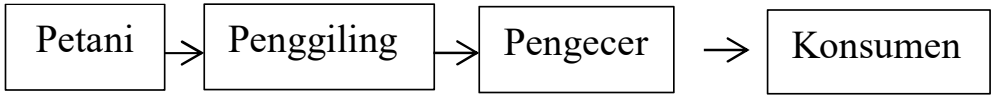

Gambar 2. Saluran II

Dari gambar II diatas dapat dilihat beras sampai ke tangan konsumen dengan melewati dua lembaga pemasaran penggiling dan pengecer. Penggiling membeli gabah basah dari petani langsung dengan sistem tebasan. Panen dan pengangkutan gabah dilakukan oleh penggiling sehingga petani tidak mengeluarkan biaya panen. Ada dua jenis padi yang ditanam oleh petani yaitu Pandan wangi dan IR64. Harga gabah basah dari penggiling ke petani Pandan Wangi Rp Rp $5.300 / \mathrm{kg}$ dan IR $64 \quad \mathrm{Rp} \quad 5.000 / \mathrm{kg}$. Pembayaran dilakukan secara tunai atau kredit tergantung kesepakatan bersama. Gabah diproses menjadi beras oleh penggiling dan dijual ke pengecer dengan harg beras Pandan Wangi Rp 11.600/kg dan beras IR64 Rp 9.500/kg. Pengecer menjual beras kepada konsumen akhir dengan harga beras Pandan Wangi Rp 12.500/kg dan beras IR64 Rp 10.600/kg.

\section{Saluran Pemasaran III}

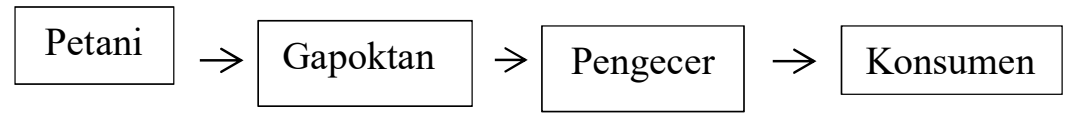

Gambar 3. Saluran III

Dari gambar III diatas dapat dilihat petani menjual hasil panen ke Gapoktan dalam bentuk gabah basah. Petani panen dan mengantar sendiri hasil panennya ke tempat Gapoktan sehingga petani mengeluarkan sendiri biaya transportasi dan biaya panen. Harga yang diperoleh petani dari penjualan melalui lembaga ini cenderung lebih mahal dari lembaga lainnya, dengan harga gabah basah Pandan Wangi Rp 5.500/kg dan IR64 Rp 5.300/kg, dengan pembayaran secara tunai. Gapoktan menggiling sendiri gabah menjadi beras kemudian menjual ke pengecer dengan harga beras Pandan wangi
Rp 12.000/kg dan beras IR64 Rp 9.800/kg. Harga jual pengecer ke konsumen beras Pandan wangi $\mathrm{Rp} 12.600 / \mathrm{kg}$ dan beras $\mathrm{Rp}$ IR64 10.900/kg.

Komponen Biaya dan Margin Pemasaran Biaya pemasaran meliputi semua rangkaian biaya dalam pemasaran atau kegiatan untuk menjual barang kepada konsumen. Dalam melakukan kegiatankegiatan pemasaran terdapat biaya dan margin pemasaran meliputi harga harga beli dari produsen dan harga jual untuk konsumen yang dapat diihat pada tabel berikut: 
Tabel 1. Harga Beli, Harga Jual, Biaya Pemasaran, Keuntungan dan Margin Pemasaran Saluran I di Kecamatan Sidorejo

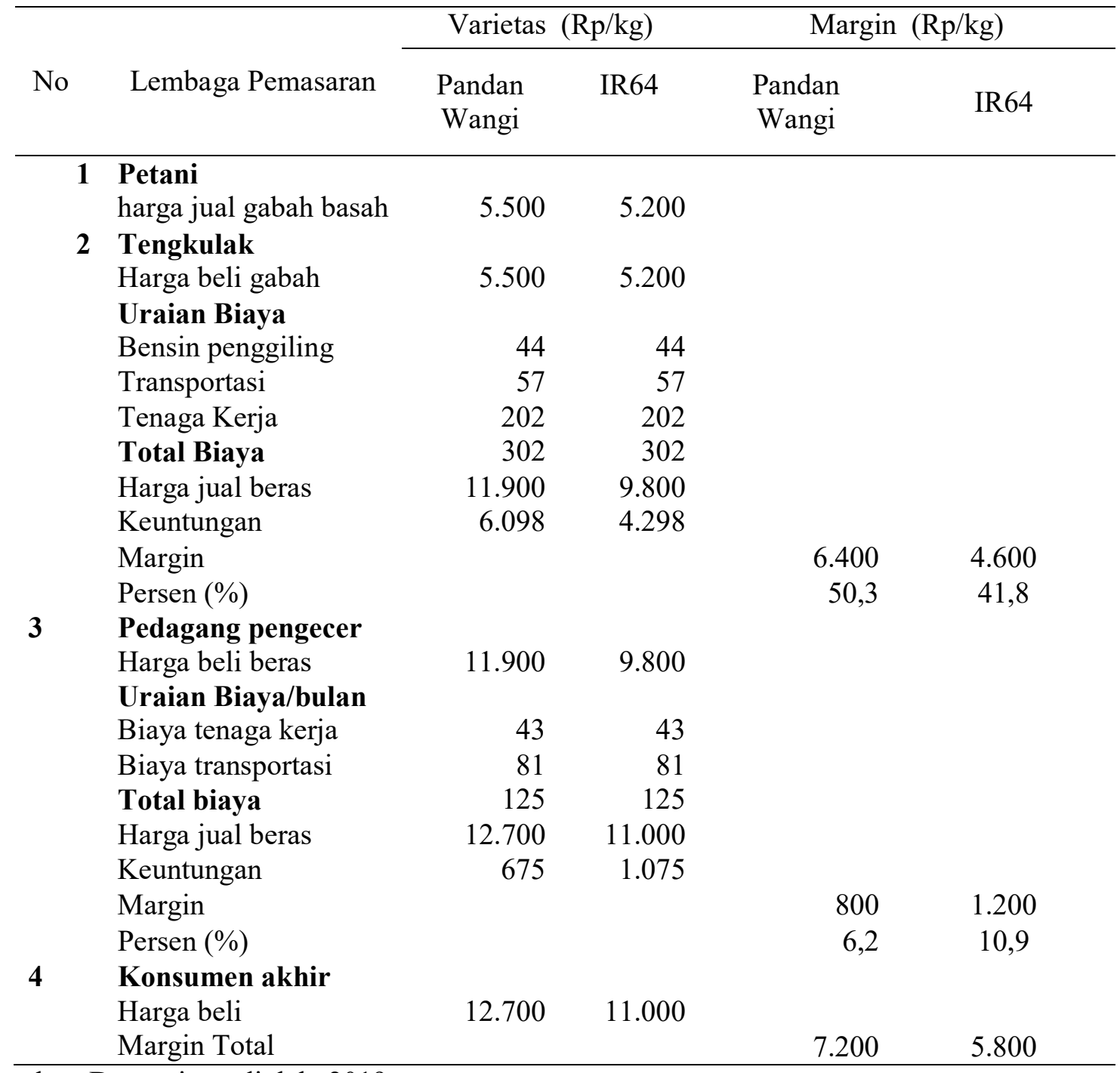

Sumber: Data primer diolah, 2019

Dari Tabel 1 saluran pemasaran I dapat dilihat margin dari petani ke tengkulak untuk beras Pandan Wangi sebesar Rp $6.400 / \mathrm{kg}$ atau sekitar $50,3 \%$ dan untuk beras IR64 sebesar Rp 4.600/kg atau sekitar $41,8 \%$ dengan biaya pemasaran beras $\mathrm{Rp}$ $302 / \mathrm{kg}$, meliputi biaya bensin penggilingan, tenaga kerja, dan biaya transportasi, dengan keuntungan untuk beras Pandan Wangi sebesar Rp 6.098/kg dan untuk beras IR64 Rp 4.298/kg. Margin pemasaran dari pengecer ke konsumen untuk beras Pandan Wangi sebesar Rp 800/kg atau sekitar 6,2\% dan untuk beras IR64 sebesar Rp 1.200/kg atau sekitar 10,9\%, dengan biaya pemasaran Rp 125/kg meliputi biaya tenaga kerja dan transportasi sehingga keuntungan yang diperoleh pedagang pengecer untuk beras Pandan Wangi sebesar Rp 675kg dan beras IR64 Rp 1.075/kg. Harga beras Pandan Wangi sampai ke konsumen akhir sebesar Rp 12.700/kg dan beras IR64 Rp11.000/kg. 
Tabel 2. Harga Beli, Harga Jual, Biaya Pemasaran, Keuntungan dan Margin Pemasaran Saluran II di Kecamatan Sidorejo

\begin{tabular}{|c|c|c|c|c|c|}
\hline \multirow[t]{2}{*}{ No } & \multirow[b]{2}{*}{ Lembaga Pemasaran } & \multicolumn{2}{|c|}{ Varietas $(\mathrm{Rp} / \mathrm{kg})$} & \multicolumn{2}{|c|}{$\operatorname{Margin}(\mathrm{Rp} / \mathrm{kg})$} \\
\hline & & $\begin{array}{c}\text { Pandan } \\
\text { Wangi }\end{array}$ & IR64 & $\begin{array}{c}\text { Pandan } \\
\text { Wangi }\end{array}$ & IR64 \\
\hline \multirow[t]{2}{*}{1} & Petani & & & & \\
\hline & harga jual gabah basah & 5.300 & 5.000 & & \\
\hline \multirow[t]{11}{*}{2} & Penggiling & & & & \\
\hline & Harga beli gabah & 5.300 & 5.000 & & \\
\hline & Uraian Biaya & & & & \\
\hline & Bensin penggiling & 42 & 42 & & \\
\hline & Transportasi & 24 & 24 & & \\
\hline & Tenaga Kerja & 170 & 170 & & \\
\hline & Total Biaya & 236 & 236 & & \\
\hline & Harga jual beras & 11.600 & 9.500 & & \\
\hline & Keuntungan & 6.064 & 4.264 & & \\
\hline & Margin & & & 6.300 & 4.500 \\
\hline & Persen (\%) & & & 50,4 & 42,4 \\
\hline \multirow[t]{10}{*}{3} & Pedagang pengecer & & & & \\
\hline & Harga beli beras & 11.600 & 9.500 & & \\
\hline & Uraian Biaya & & & & \\
\hline & Biaya tenaga kerja & 63 & 63 & & \\
\hline & Biaya Transportasi & 94 & 94 & & \\
\hline & Total biaya & 157 & 157 & & \\
\hline & Harga jual beras & 12.500 & 10.600 & & \\
\hline & Keuntungan & 743 & 943 & & \\
\hline & Margin & & & 900 & 1.100 \\
\hline & Persen $(\%)$ & & & 7,2 & 10,3 \\
\hline \multirow[t]{3}{*}{4} & Konsumen akhir & 12.500 & 10.600 & & \\
\hline & Harga beli & & & & \\
\hline & Margin Total & & & 7.200 & 5.600 \\
\hline
\end{tabular}

Sumber: Data primer diolah, 2019

Dari Tabel 2 saluran pemasaran II dapat dilihat margin dari petani ke penggiling untuk beras Pandan Wangi sebesar $\mathrm{Rp} 6.300 / \mathrm{kg}$ atau sekitar $50,4 \%$ dan beras IR64 sebesar Rp 4.500/kg atau sekitar 42,4\% dengan biaya pemasaran Rp 236/kg meliputi biaya bensin penggilingan, tenaga kerja, dan transportasi dengan keuntungan untuk beras Pandan Wangi sebesar Rp $6.064 / \mathrm{kg}$ dan untuk beras IR64 sebesar Rp $4.264 / \mathrm{kg}$. Margin pemasaran dari pengecer ke konsumen untuk beras Pandan Wangi sebesar Rp 900/kg atau sekitar 7,2\% dan untuk beras IR64 Rp 1.100/kg atau sekitar $10,3 \%$ dengan biaya pemasaran $\mathrm{Rp} 157 / \mathrm{kg}$ meliputi biaya tenaga kerja, dan transportasi sehingga keuntungan yang di peroleh pedagang pengecer untuk beras Pandan Wangi sebesar Rp 743/kg dan untuk beras IR64 sebesar Rp 943/kg. Harga beras Pandan Wangi sampai ke konsumen akhir sebesar Rp 12.500/kg dan beras IR64 sebesar Rp10.600/kg. 
Tabel 3. Harga Beli, Harga Jual, Biaya Pemasaran, Keuntungan dan Margin Pemasaran Saluran III di Kecamatan Sidorejo

\begin{tabular}{|c|c|c|c|c|c|}
\hline \multirow[b]{2}{*}{ No } & \multirow[b]{2}{*}{ Lembaga Pemasaran } & \multicolumn{2}{|c|}{ Varietas $(\mathrm{Rp} / \mathrm{kg})$} & \multicolumn{2}{|c|}{ Margin $(\mathrm{Rp} / \mathrm{kg})$} \\
\hline & & $\begin{array}{c}\text { Pandan } \\
\text { Wangi }\end{array}$ & IR64 & $\begin{array}{c}\text { Pandan } \\
\text { Wangi }\end{array}$ & IR64 \\
\hline \multirow[t]{2}{*}{1} & Petani & & & & \\
\hline & Harga jual gabah basah & 5.500 & 5.300 & & \\
\hline \multirow[t]{11}{*}{2} & Gapoktan & & & & \\
\hline & Harga beli gabah & 5.500 & 5.300 & & \\
\hline & Uraian Biaya & & & & \\
\hline & Bensin penggiling & 45 & 45 & & \\
\hline & Transportasi & - & - & & \\
\hline & Tenaga Kerja & 183 & 41 & & \\
\hline & Total Biaya & 228 & 228 & & \\
\hline & Harga jual beras & 12.000 & 9.800 & & \\
\hline & Keuntungan & 6.272 & 4.272 & & \\
\hline & Margin & - & - & 6.500 & 4.500 \\
\hline & Persen $(\%)$ & - & - & 51,5 & 41,2 \\
\hline \multirow[t]{10}{*}{3} & Pedagang pengecer & & & & \\
\hline & Harga beli beras & 12.000 & 9.800 & & \\
\hline & Uraian Biaya & & & & \\
\hline & biaya Tenaga kerja & 51 & 51 & & \\
\hline & Biaya Transportasi & 85 & 85 & & \\
\hline & Total biaya & 137 & 137 & & \\
\hline & Harga jual beras & 12.600 & 10.900 & & \\
\hline & Keuntungan & 463 & 963 & & \\
\hline & Margin & & & 600 & 1.100 \\
\hline & Persen $(\%)$ & & & 4,7 & 10,0 \\
\hline \multirow[t]{3}{*}{4} & Konsumen akhir & & & & \\
\hline & Harga beli & 12.600 & 10.900 & & \\
\hline & Margin Total & & & 7.100 & 5.600 \\
\hline
\end{tabular}

Sumber: Data primer diolah, 2019

Dari Tabel 3 saluran pemasaran III dapat dilihat margin dari petani ke Gapoktan untuk beras Pandan Wangi sebesar Rp $6.500 / \mathrm{kg}$ atau sekitar $51,5 \%$ dan untuk beras IR64 sebesar Rp 4.500/kg atau sekitar 41,2\% dengan biaya pemasaran $\mathrm{Rp} 228 / \mathrm{kg}$ meliputi biaya bensin penggiling dan tenaga kerja, dengan keuntungan untuk beras Pandan Wangi sebesar $6.272 / \mathrm{kg}$ dan untuk beras IR64 sebesar Rp 4.272/kg. Margin pemasaran dari pengecer ke konsumen untuk beras Pandan Wangi sebesar Rp 600/kg atau sekitar 4,7\% dan untuk beras IR64 sebesar $\mathrm{Rp} 1.100 / \mathrm{kg}$ atau sekitar $10,0 \%$ dengan biaya $\mathrm{Rp} \mathrm{137/kg} \mathrm{meliputi} \mathrm{biaya} \mathrm{tenaga} \mathrm{kerja}$ dan transportasi. Keuntungan yang diperoleh dari beras Pandan Wangi sebesar Rp 463/kg dan beras IR64 sebesar Rp 963/kg. Harga beras Pandan Wangi sampai ke konsumen akhir sebesar Rp 12.600/kg dan untuk beras IR64 Rp10.900/kg.

\section{Margin Untuk Setiap Lembaga Pemasaran}

Margin pemasaran digunakan untuk mengetahui perbedaan pendapatan yang diterima oleh setiap lembaga tataniaga di setiap saluran pemasaran. Berikut perhitungan margin setiap saluran 
pemasaran. Berdasarkan Tabel 4 dapat dilihat berapa besar margin setiap lembaga pemasaran. Nilai margin pemasaran terbesar terdapat pada lembaga pemasaran saluran II yaitu untuk beras Pandan Wangi sebesar Rp $7.200 / \mathrm{kg}$ atau sekitar 57,6\% dan beras IR64 sebesar Rp 5.600/kg atau sekitar 52,8\%.

Tabel 4. Margin Lembaga Pemasaran

\begin{tabular}{lcccc}
\hline \multirow{2}{*}{ Saluran Pemasaran } & Pandan Wangi & IR64 & Pandan Wangi & IR64 \\
& ------------(Rp/kg)----------- & $--------------(\%)$ \\
\hline Saluran I & 7.200 & 5.800 & 56,7 & 52,7 \\
Saluran II & 7.200 & 5.600 & 57,6 & 52,8 \\
Saluran III & 7.100 & 5.500 & 56,3 & 51,4 \\
\hline
\end{tabular}

Sumber: Data primer diolah, 2019

\section{Farmers' Share}

Farmer's share merupakan persentase bagian yang diterima oleh petani padi dari harga yang berlaku pada pedagang pengecer. Besar kecilnya farmer's share dipengaruhi oleh panjang saluran dan besarnya harga jual pada pedagang pengecer. Perhitungan farmer's share dengan menghitung harga di tingkat petani di bagi dengan harga ditingkat pengecer lalu dikali $100 \%$. Perhitungan farmer's share pada setia saluran pemasaran dapat dilihat dari Tabel 4.. Lembaga pemasaran yang memiliki nilai farmer's share terbesar terdapat pada saluran III yaitu melalui Gapoktan untuk beras Pandan Wangi sebesar 43,7\% dan beras IR64 sebesar $48,6 \%$.

Tabel 5. Farmers Share Saluran Pemasaran I, II dan III di Kecamatan Sidorejo

\begin{tabular}{ccccccc}
\hline & \multicolumn{2}{c}{$\begin{array}{c}\text { Harga Petani } \\
(\mathrm{Rp} / \mathrm{kg})\end{array}$} & \multicolumn{2}{c}{$\begin{array}{c}\text { Harga Konsumen } \\
(\mathrm{Rp} / \mathrm{kg})\end{array}$} & \multicolumn{2}{c}{$\begin{array}{c}\text { Farmer's share } \\
(\%)\end{array}$} \\
\cline { 2 - 7 } $\begin{array}{c}\text { Lembaga } \\
\text { Pemasaran }\end{array}$ & $\begin{array}{c}\text { Pandan } \\
\text { Wangi }\end{array}$ & IR64 & $\begin{array}{c}\text { Pandan } \\
\text { Wangi }\end{array}$ & IR64 & $\begin{array}{c}\text { Pandan } \\
\text { Wangi }\end{array}$ & IR64 \\
\hline Tengkulak & 5.500 & 5.200 & 12.700 & 11.000 & 43,3 & 47,3 \\
Penggiling & 5.300 & 5.000 & 12.500 & 10.600 & 42,4 & 47,2 \\
Gapoktan & 5.500 & 5.300 & 12.600 & 10.900 & 43,7 & 48,6 \\
\hline
\end{tabular}

Sumber: Sumber: Data primer diolah, 2019

\section{Efesiensi Pemasaran}

Efesiensi pemasaran merupakan akhir dari keseluruhan aktifitas pemasaran di mana dapat diketahui saluran mana yang efisien untuk dijalankan. Sehingga berdasarkan Tabel 6 saluran efisien pemasaran di bawah beras di Kecamatan Sidorejo melalui tiga saluran pemasaran yaitu saluran I memiliki nilai efisiensi pemasaran yaitu untuk beras Pandan Wangi sebesar 33,6\% dan untuk beras IR64 sebesar $38,8 \%$, saluran II untuk beras Pandan Wangi sebesar 31,4\% dan untuk beras IR64 sebesar $37,0 \%$ dan saluran III untuk beras Pandan Wangi sebesar 29,8\% dan untuk beras IR64 sebesar 33,4\%. 
Tabel 5 Efesiensi Saluran Pemasaran Beras I, II dam III di Kecamatan Sidorejo

\begin{tabular}{|c|c|c|c|c|c|c|c|}
\hline \multirow{3}{*}{ No } & \multirow{3}{*}{ Saluran Pemasaran } & \multicolumn{4}{|c|}{ Keterangan } & \multirow{2}{*}{\multicolumn{2}{|c|}{ Efisiensi (\%) }} \\
\hline & & \multicolumn{2}{|c|}{$\begin{array}{l}\text { Biaya pemasaran } \\
(\mathrm{Rp} / \mathrm{kg})\end{array}$} & \multicolumn{2}{|c|}{$\begin{array}{l}\text { Harga Jual } \\
(\mathrm{Rp} / \mathrm{kg})\end{array}$} & & \\
\hline & & $\begin{array}{l}\text { Pandan } \\
\text { wangi }\end{array}$ & IR64 & $\begin{array}{c}\text { Pandan } \\
\text { wangi }\end{array}$ & IR64 & $\begin{array}{l}\text { Pandan } \\
\text { wangi }\end{array}$ & IR64 \\
\hline 1 & Saluran I & 427 & 427 & 12.700 & 11.000 & 33,6 & 38,8 \\
\hline 2 & Saluran II & 393 & 393 & 12.500 & 10.600 & 31,4 & 37,0 \\
\hline 3 & Saluran III & 365 & 365 & 12.600 & 10.900 & 29,8 & 33,4 \\
\hline
\end{tabular}

Sumber: Data Primer Setelah Diolah, 2019

\section{KESIMPULAN DAN SARAN}

\section{Kesimpulan}

Berdasarkan hasil penelitian dan pembahasan di kecamatan Sidorejo dapat disimpulakan :

1. Pola saluran pemasaran terdiri dari 3 saluran

Saluran I: Petani - Tengkulak - Pengecer - Konsumen, saluran II : Petani Penggiling - Pengecer - Konsumen, saluran III : Petani - Gapoktan - Pengecer - Konsumen

2. Margin pemasaran yang paling tinggi terdapat pada saluran II yaitu untuk beras Pandan Wangi sebesar $7.200 / \mathrm{kg}$ atau sekitar 57,6\% dan untuk beras IR64 Rp $5.600 \mathrm{~kg}$ atau sekitar $52,8 \%$ kemudian saluran I untuk beras Pandan Wangi sebesar Rp 7.200/kg atau sekitar 56,7\% dan untuk beras IR64 sebesar Rp $5.600 / \mathrm{kg}$ atau sekitar 52,7\%, dan terakhir margin paling rendah melalui Saluran III yaitu untuk beras Pandan Wangi sebesar Rp 7.100/kg atau sekitar 56,3\% dan untuk beras IR64 sebesar Rp 5.600/kg atau sekitar 51,4\%.

3. Nilai farmer's share terbesar terdapat pada saluran III yaitu untuk beras Pandan Wangi sebesar 43,7\% dan beras IR64 sebesar $48,6 \%$.

4. Saluran pemasaran yang paling efisien terdapat pada saluran pemasaran III dengan nilai efisien untuk beras Pandan Wangi 29\% dan beras IR64 33,4 \%.

\section{Saran}

1. Memperkuat kelembagaan Gapoktan dalam pengolahan beras sehingga dapat menampung hasil produksi petani, dikarenakan gapoktan memberi harga yang lebih tinggi dari saluran pemasaran lainnya sehingga dapat meningkatkan pendapatan petani.

2. Salah satu alternatif agar petani padi memperoleh keuntungan dalam pemasaran hasil panen dengan menjual padi menjadi beras secara langsung ke konsumen.

\section{DAFTAR PUSTAKA}

Anindita,R. 2003. "Dasar-dasar Pemasaran Hasil Pertanian". Universita Brawijaya, Malang.

BPS. 2008. Statistik Indonesia. Badan Pusat Statistik. Jakarta

Dinas Pertanian. 2017. Buku Saku Dinas Pertanian Tahun 2016 Tahun Anggaran 2017.

Handayani, S.M dan I. Nurlaila. 2011. Analisis pemasaran Susu Segar di Kabupaten Klaten. Jurnal Sains Peternakan. 9 (1): 41-52

Hildayani, R., 2013. Analisis Pemasaran Beras Di Desa Sidondo Kecamatan Sigi Biromaru Kabupaten Sigi. e-J. Agrotekbis 1 (5) : 485 - 492 
Jayanti, Mika. 2011. Faktor-faktor Yang Mempengaruhi Keputusan Petani Padi Sawah Menggunakan Benih Menurut Sumber Benih. Skripsi Program Studi Agribisnis.

Malian, A.Husni.2004. Faktor-Faktor Yang Mempengaruhi Produksi, Konsumsi, Dan Harga Beras Serta Inflasi Bahan Makanan. Pusat Penelitian dan Pengembangan Sosial Ekonomi Pertanian, Bogor.

Nurasa,T., dan Darwis, V. 2007. Analisis Usahatani dan Keragaan Marjin Pemasaran Bawang Merah di Kabupaten Brebes. Jurnal Akta Agrosia, 10 No.1. hl. 40-48.
Sudiyono, 2004. Pemasaran Pertanian. Universitas Muhammadiyah Malang Pres, Malang.

Soekartawi. 2002. Aanalisis Usahatani. Jakarta: Universitas Indonesia

Tambunan, Tulus. 2008. "Tataniaga dan Pengendalian Harga Beras di Indonesia" 